\title{
Nurse practitioners knowledge, attitudes, and self-efficacy for working with transgender patients
}

\author{
Pamela J. Levesque \\ School of Nursing, University of North Carolina-Wilmington, Wilmington, NC, U.S.A.
}

Correspondence: Pamela J. Levesque. Address: School of Nursing, University of North Carolina-Wilmington 601 South College Drive Wilmington, NC 28403-5995, U.S.A. Email: levesquep@uncw.edu

Received: September 16, 2013

Accepted: November 14, 2013

Online Published: November 24, 2013

DOI : $10.5430 /$ cns.v1n4p93

URL: http://dx.doi.org/10.5430/cns.v1n4p93

\begin{abstract}
Lesbian, gay, bisexual, and transgender (LGBT) people experience distinct health disparities and are one of the largest underserved populations in any nursing setting. Transgender health has been the subject of relatively little health research, particularly within the nursing community. Studies investigating nursing's knowledge and attitudes towards LGBT persons suggest a gap that can affect the access and quality of care for transgender patients. The purpose of this pilot descriptive study was to explore nurse practitioner knowledge, attitudes and self-efficacy in caring for transgender persons; those whose gender identity and/or gender expression does not fit their gender assigned at birth (natal gender). Bandura's theory of self-efficacy was used as the theoretical framework. Using a sample of nurse practitioners $(n=416)$ that provided email addresses to a nurse practitioner association questionnaires were delivered electronically which were designed to measure knowledge, attitude and self-efficacy for providing transgender health care. Twenty-six completed surveys were returned. The results indicated that the majority of the respondents' state "full respect" and "acceptance" towards transgender patients while also reporting low self-efficacy for providing care. All respondents report no transgender content during their nurse practitioner education. Implications from this study suggest that nurse practitioners hold attitudes that promote culturally competent care while knowledge and self-efficacy are potential areas of need. Further clinical research is needed investigating nurse practitioner knowledge, attitude and self-efficacy on a larger scale while also investigating gender and sexual minority content in nursing educational programs.
\end{abstract}

\section{Key words}

Self-efficacy, Transgender, Attitudes, Knowledge, Nurse practitioner

\section{I ntroduction}

Lesbian, gay, bisexual, and transgender (LGBT) people experience distinct health disparities and are one of the largest underserved populations in any nursing setting ${ }^{[1,2]}$. The acronym LGBT is a collective term, each letter representing a distinct population with its own health care concerns. This research focused on the "T" of LGBT. Transgender is an umbrella term referring to people whose gender identity and/or gender expression does not fit their gender assigned at birth (natal gender). Transgender health has been the subject of relatively little health research, particularly within the nursing 
community ${ }^{[2,3]}$. Several studies investigating registered nurse and/or nursing student knowledge and attitudes towards LGBT persons suggest a gap in these areas that can affect access and quality of patient care ${ }^{[4,5]}$.

Over the past few decades clinicians have become increasingly aware that transgender individuals may have unique health needs but may be uncertain as to what they are or how to begin to address them ${ }^{[6]}$. This recognition has led to research examining potential health disparities. Both The National Transgender Discrimination Survey ${ }^{[7]}$ and The Institute of Medicine (IOM) report ${ }^{[3]}$. The Health of Lesbian, Gay, Bisexual, and Transgender People:building a foundation for better understanding acknowledged insufficient provider understanding concerning LGBT health care need ${ }^{[6]}$. The United States Federal Government Healthy People 2020 (HP2020) initiative emphasizes the elimination of health disparities and states that through culturally competent care the U.S. can provide equal access to health care for all with the specific goal of improving the health, safety, and well-being of lesbian, gay, bisexual and transgender persons ${ }^{[8]}$.

What we know from the research is that culturally sensitive care is essential and influences personal access to health care. Culturally sensitive care includes but is not limited to (gender) attitudes and knowledge which can influence personal access to health care ${ }^{[9]}$. There are numerous reports that validate gender discrimination in health care, the 2009 IOM study being one, suggesting that provider's beliefs and attitudes about the client may be perhaps the least examined aspect of care ${ }^{[10]}$. The attitudes, feelings and beliefs that providers hold about their patients may have far reaching effects on the services they provide. Examination of nursing and medical school education has revealed gaps concerning LGBT content in the curriculum which rarely includes the importance of understanding personally held beliefs about the patients for whom they are to provide care ${ }^{[11-13]}$. It is written that attitudes are recognized as the most difficult component to change ${ }^{[14]}$. A study by Kitts published in 2010 looked at knowledge and attitudes for lesbian, gay, bisexual transgender and questioning adolsecents (LGBTQ) by resident' and attending physicians'. A total of 464 anonymous, selfadministered surveys were were returned. The survey results suggested that barriers to providing optimal care for LGBTQ adolescents can be found with regard to practice, knowledge, and attitude regardless of medical field and other demographics collected. It should be mentioned however, that the instruments used by Kitts were LGB specific and did not include transgender.

A concept analysis on personal access to health care by ${ }^{[15]}$ addresses four attributes critical to the understanding of personal access to health care. The four attributes identified are: availability, eligibility, amenability and compatibility. This analysis offers a definition of personal access to health care that may help to understand the missing pieces of transgender health care access. Self-reported experiences of discrimination and fear of discrimination have been linked to a negative impact on both physical and mental health outcomes ${ }^{[16,17]}$. The experience of discrimination and fear of discrimination may be linked to attitudes, knowledge and self-efficacy on the part of the heatlh care provider.

Heterosexism as a attitude barrier is in fact the most common form of discrimination in the health care system ${ }^{\text {[16] }}$. In a concept analysis entitled "Heterosexism and Health Care" the definition for heterosexism includes two characteristics: one is a belief that heterosexual relationships are to be assumed, are preferred, and are normal, and secondly, that heterosexism is a socio-political concept apparent in laws, policies, and procedures whereby the heterosexual majority actively or passively excludes and discriminates against the non-heterosexual minority ${ }^{[18]}$. The heterosexism assumption can be internalized by a provider as a predominant view of which they are unaware. Brotman, Ryan, Jalbert and Rowe ${ }^{[16]}$ and Balsam, Molina, Beadnell, Simoni, and Walters ${ }^{[19]}$ have written that heterosexist reactions can be categorized as microaggressions which range from ostracism to invasive questioning, shock, embarrassment, unfriendliness, pity, condescension and fear. Microaggressions can be from one or all of three of these categories; microassaults, microinsults, or microinvalidations ${ }^{[19]}$. The consequence of non-disclosure from a sense of provider heterosexism may lead to a feeling of alienation and inadequate treatment as gender self-disclosure improves the chances of receiving appropriate and satisfactory health care. 
Transgender persons have been found to confront additional barriers which include insufficient numbers of providers with transgender health knowledge and structural barriers that impede access and medical decision-making rights (IOM, pg 64); as well as a lack of culturally appropriate prevention services ${ }^{[6]}$. Documented consequences from these barriers to health care are presented in the 2010 publication, Injustice at Every Turn: A report of the National Transgender Discrimination Survey. These health consequences include higher rates of cancer, thromboembolitic disease in non-medically supervised hormone use, higher risk of mental health disorders, high rates of tobacco use, suicide, high-risk behavior from absent health promotion and prevention practices, and alcoholism ${ }^{[3,17,19]}$.

While there is scant research investigating registered nurse's attitudes and knowledge towards transgender persons there is no data addressing the held knowledge, attitudes and self-efficacy towards transgender persons by nurse practitioners (NPs). NPs are registered nursing professionals who have master's or doctoral level education in a specific specialty and are board eligible or certified in their chosen specialty such as anesthesia, psychiatric, gerontology, family, pediatric, or acute care. NPs have an autonomous practice at an advanced level and perform in a variety of roles in both primary and acute care settings. According to the American Academy of Nurse Practitioners ${ }^{[20]}$, in 2010 there were approximately 140,000 nurse practitioners practicing in the United States in all states in the following distribution categories: 63\% family, $21 \%$ adult, $7 \%$ acute care and the remainder in women's health, pediatrics, oncology and other specialties ${ }^{\text {[21] }}$. Identifying nurse practitioners' knowledge, attitudes, and self-efficacy about gender culturally sensitive care is essential when assessing for transgender access and quality health care obstacles because of their visible presence in the health care community in diverse specialty areas. Nurse practitioners that may hold heterosexual assumptions towards patients compete against potentially supportive provider/client interactions which may consequenctly have a negative impact on care ${ }^{[22,23]}$. This aim of this research was to add to the nursing body of knowledge in an area where there is an identified gap: nurse practitioners' knowledge, attitude and self-efficacy towards transgender persons.

\section{Method}

This descriptive survey explored the knowledge, attitudes and self-efficacy of nurse practitioners for providing health care to transgender persons. In addition to a demographic questionnaire, there were two surveys used; the Attitude Towards Transgender Survey (ATS) by Swanstrom ${ }^{[24]}$ and the Health Care Provider Survey by Burch (HCPS) ${ }^{[22]}$. The ATS is a 47-question survey which gathers information soley related to attitude. The ATS uses a Likert summated ratings scale where 1 equals strongly agree, 2 equals agree, 3 is minimally agree, 4 represents minimally disagree, 5 is disagree and 6 is strongly disagree. The HCPS developed by Burch ${ }^{[22]}$ is 21 questions made up of fill in the blank, Likert scale questions and binary questions. The HCPS gathers information on provider knowledge, attitudes and self-efficacy when delivering transgender health care.

Data collection occurred via an electronically delivered questionnaire which was distributed by a state nurse practitioner association via email to all $(n=416)$ current members of the association that provided email addresses. The data from the questionnaires were downloaded into Standard Package for Statistical Sciences (SPSS) for statistical testing. Descriptive statistics including measures of central tendency and distribution were used from the demographic data to create a profile of the respondents and to present findings from the Health Care Provider Survey and Attitude Towards Transsexuals Survey related to the key variables of knowledge, attitudes and self-efficacy. ANOVA and t-test were not performed because the assumptions concerning distribution and sample size were not present.

Pearson correlation coefficient was used to examine the relationship between self-efficacy, knowledge and attitudes and the demographic variables of age, education, specialization, sexual orientation, years of practice and employment setting. Regression analysis was used to explore any association between the variables. 


\section{Results}

The link to the reserach survey was sent to a convenience sample $(n=416)$ twice at two week increments during the month of May. Of the 416 potential respondents 34 read the consent, one did not consent. Of the 33 providing informed consent 29 continued on to the survey questions (6.97\%) until question 6 when respondents dropped to 28 (6.73\%). Another drop appeared at question 25 ( $\mathrm{n}=27$ ) questions 26-30 had 28 respondents. Question 31 had 26 answers; $32-34$ had 27 and the remainder, from question 35 on, had 26 respondents for a final total of $n=26$ (6.25\%). All responses to each question throughout the survey are included which is seen as a variable $\mathrm{n}$ throughout reported results.

The mean age sample completing the demographic questions ( $n=29)$ was 50.86 years (29-71 years) and they were predominantly white $(n=27,79.4 \%)$ and female $(n=28,96.6 \%)$. The majority of nurse practitioners in the study worked in primary care $(n=14,50 \%)$ with acute care $(n=13,46.3 \%)$ as the second most frequently listed employment setting; family nurse practitioner was reported as the most common specialty area. Table 1 displays demographic characteristics.

Table 1. Demographic characteristics of participants $(n=28 / 29)$

\begin{tabular}{|c|c|c|}
\hline Characteristic & $\mathbf{n}$ & $\%$ \\
\hline \multicolumn{3}{|c|}{ Years as a nurse practitioner } \\
\hline $1-5$ & 10 & 34.48 \\
\hline $6-10$ & 3 & 10.34 \\
\hline $11-14$ & 7 & 24.14 \\
\hline $16-20$ & 5 & 17.24 \\
\hline $20+$ & 4 & 13.79 \\
\hline \multicolumn{3}{|l|}{ Race or Ethnicity } \\
\hline White & 27 & 96.43 \\
\hline Black & 1 & 3.47 \\
\hline \multicolumn{3}{|c|}{ Religion or Spiritual Practice } \\
\hline No & 9 & 32.14 \\
\hline Yes & 19 & 67.86 \\
\hline \multicolumn{3}{|l|}{ Gender } \\
\hline Female & 28 & 96.55 \\
\hline Male & 1 & 3.45 \\
\hline \multicolumn{3}{|l|}{ Sexual Preference } \\
\hline Bisexual & 2 & 7.14 \\
\hline Female & 2 & 7.14 \\
\hline Heterosexual & 20 & 71.33 \\
\hline Male & 1 & 3.57 \\
\hline Prefer Men & 1 & 3.57 \\
\hline Strait & 1 & 3.57 \\
\hline What & 1 & 3.57 \\
\hline \multicolumn{3}{|l|}{ Age } \\
\hline $29-35$ & 5 & 17.24 \\
\hline $43-50$ & 7 & 24.14 \\
\hline $51-56$ & 6 & 20.69 \\
\hline 57-62 & 8 & 27.59 \\
\hline 63-71 & 3 & 10.34 \\
\hline
\end{tabular}

Attitudes towards transgender persons was investigated using the Attitude Towards Transgender Survey ( $\alpha=0.98)$ (ATS) by Swanstrom ${ }^{[24]}$ and the Health Care Provider Survey (HCPS) ( $\alpha=0.67$ ) by Burch (HCPS) (2005). Assumptions associated with t-test must be fulfilled for statistical validity. Those assumptions include: data approximate to the normal distribution, groups are independent (unrelated), and a study size should be 30 or greater ${ }^{\text {[25] }}$. Because of the low response 
rate and data distribution these assumptions were not met and as such this test was not used to interpret the data. The ATS questions were aggregated to create an attitude dimension with 47-items. The 47 items were coded as 1 representing negative attitude, 2 representing a neutral attitude and 3 signifying a positive attitude. Findings indicated that $74.1 \%$ $(\mathrm{n}=20)$ chose "3" signifying a positive attitude.

The HCPS measured attitude with a single question: How would you describe your attitudes/beliefs towards working with transgender patients? This question had four choices, the highest being full acceptance and the lowest being "I find it difficult to have tolerance for transgender patients". The HCPS showed 82.1\% $(n=23)$ selecting "I have full respect and acceptance for transgender patients"; 10.7\% (n=3) selected "I have some respect and acceptance for transgender patients" and 7.1\% (n=2) chose "I have tolerance for transgender patients".

Self-efficacy was measured by the HCPS and is defined as the belief in one's capabilities to organize and execute courses of action ${ }^{[26]}$. Summary confidence ratings to the HCPS question "How confident are you that your educational background prepared you to provide services for transgender persons?" are in Table 2. Inspection of the data revealed that individuals were significantly less confident $(n=9 ; 32.1 \%$ at $0 \%$ confident and $n=6 ; 53.6 \%$ at $20 \%$ confidence) that their NP educational background prepared them to provide health care to transgender persons.

Table 2. Responses to HCPS Self-Efficacy Survey Question, "How Confident Are You That Your Educational Background Prepared You To Provide Services for Transgender Persons?”

\begin{tabular}{lll}
\hline Response & n & \% \\
\hline 1=0\% Confident & 9 & 32.1 \\
$2=20 \%$ Confident & 6 & 53.6 \\
$3=40 \%$ Confident & 4 & 14.3 \\
$4=60 \%$ Confident & 5 & 17.9 \\
$5=80 \%$ Confident & 4 & 14.3 \\
$6=100 \%$ Confident & 0 & 0 \\
\hline
\end{tabular}

Research question three from the HCPS addressed NPs knowledge for providing culturally competent transgender health care by asking, the following questions from the HCPS: How would you rate your level of knowledge about transgender health needs? How would you rate your level of knowledge about transgender person's lifestyle in general? Knowledge is described as an understanding of, and is also used by Burch in her 2008 study developing the HCPS. Comparing the results of the two questions, one addressing knowledge of health care needs and the other knowledge about transgender person's lifestyle in general, shows that no one selected "very high" level of knowledge for either question. The most frequently selected answer was "average" level of knowledge for both questions. Inspection of the data showed the respondents believed themselves to have an average knowledge level based on these two questions which assessed knowledge level towards transgender health care needs and knowledge of transgender lifestyle.

Of note is an additional finding from the HCPS question, "Have you ever considered that the patients you work with may be transgender?" where $89.3 \%(n=25)$ of survey respondents replied that they have considered that the patients they work with may be transgender. This a contrast to the finding by Burch's original study in 2005 where seventy-nine percent of the respondents reported that they had never considered that the patient being cared for may be LGBT.

Question four investigated any potential relationship between knowledge, attitudes and self-efficacy as measured by the Health Care Provider Survey and Attitudes Towards Transsexual Scale. Knowledge was composed of 2 items, attitude was composed of 47 items and self-efficacy was composed of 1 item. An inverse relationship was found between attitude and self-efficacy; as attitude positively increased, self-efficacy decreased ( $r=-.605, p=.001)$. The same findings were true for 
attitude and knowledge; an inverse relationship where as knowledge increased, attitude decreased $(r=-.429, p=.026)$. There was no relationship found between knowledge and self-efficacy.

Question five asked to what extent knowledge, attitude and self-efficacy are described by demographics of age, education, specialization, gender, sexual orientation, years of practice and employment setting. Visual inspection of the variables revealed that gender ( $n=1 /$ male) and race $(n=1 /$ black) did not demonstrate the representative sample to run correlational data. The minimum power suggested for correlational analysis is $n=30^{[25]}$. This study falls below this threshold $(n=<30)$ and results should be examined without inference. The relationship between knowledge, attitude and self-efficacy was explored using Stepwise Multiple Regression. The regression revealed that the demographic variables, employment, sexual preference, years as a nurse practitioner, religion or spiritual practice identification and age did not imply a significant variance in knowledge.

\section{Discussion}

The results from this study suggest an overall acceptance towards transgender patients by the nurse practitioner respondents but imply a low self-efficacy or confidence for providing transgender health care by nurse practitioners. This is congruent with the findings from Burch ${ }^{[22]}$ in her original knowledge, attitude and self-effiacy study. Swanstrom (2006) developed the ATS using undergraduate psychology students at a state university. Findings demonstrated upper-level students responded more favorably than those in the introductory classes. The demographic differences between those participating in the ATS and the current research are such that comparisons can not be made. Considering the current study's results Bandura's theory would suggest a limited ability to perform competently and effectively. This coupled with what appears to be a low rating of transgender health care knowledge with $35.7 \%$; $n=10$, rating their level of knowledge at low, may imply, according to Bandura, a potentially anxious approach, or avoidance, to caring for transgender patients. Self-efficacy research has shown that those with low self-efficacy approach intimidating situations nervously which further lowers their sense that they will be able to perform well. It has been argued that people demonstrate avoidant behavior because of fear and that anticipatory fear controls avoidance behavior ${ }^{[26]}$. Whle fear avoidance was not included in this study the concept is suggestive of beahviors that could impact transgender care delivery and warrant further investigation.

Findings from this study imply a gap in transgender health care content in nurse practitioner education and in continuing education opportunities. Burch's 2005 study also revealed a lack of formal transgender health content in the respondent's education. However the HCPS original research findings by Burch ${ }^{[22]}$ showed fifty-nine percent reporting that the diversity training they had received post-graduation included gender and sexual minority health content. This was not the case with the current study where respondents revealed a gap in gender care content in conferences and other training sought out for cultural competency. Current study results imply that low self-efficacy and knowledge may be linked to lack of transgender health care content in nurse practitioner curricula as well as a lack of transgender health content in continuing education offerings. The gap in the nursing research concerning the provision of culturally competent health care to those that represent sexual and gender minorities has been well documented in the nursing literature ${ }^{[1,4]}$. Despite the identification of this gap and the known negative consequences of culturally deficient health care there continues to be a lag in nursing education to incorporate transgender content in undergraduate and graduate curricula. Educating new providers who are able to deliver culturally safe health care may require curriculum enhancements. Structured learning opportunities that include transgender speakers and experts on content with attention to affective learning is essential. It has been suggested that affective beliefs are the most difficult to change. Affective teaching is at the core of all care pedagogy and is recommended for inclusion in nursing education at all levels ${ }^{[27]}$ Nurse educators are responsible for crafting curriculum content and attention to their development in the area of sexual and gender minoriites may be key to incuding the content in nursing education. Schools of nursing, nurse educator programs, health provider conferences and nursing organizations should take a clear advocacy stance on social justice in education by including position statements which embrace sexual and gender minotirites while integrating content in all educational activities. Using an inter- 
disciplinary approach to building provider capacity in respectful and competent transgender health care will help to produce a nondiscriminatory transgender health care system which will improve the quality of health care for transgender patients and communities. This research represents the first of its kind to explore the knowledge, attitudes and self-efficacy of nurse practitioners for working with transgender persons and suggests that efforts such as those suggested here related to enhancing NP transgender care proficiency may potentially influence culturally competent transgender health care.

The limitations to the research study include a low respondent rate from one area of the United States, a lack of standardized definitions for use with ratings in the HCPS, limited use and testing of both the HCPS and ATS scales in general and the length of the scales when used together. Additional limitations include few questions in the HCPS addressing self-efficacy assessment specifically related to providing transgender care and the inability to return to the online survey unless the respondent activates cookies and returns to the same computer.

\section{Conclusions}

This research begins to explore the questions of knowledge, attitudes, and self-efficacy in providing culturally competent transgender health care by nurse practitioners. Findings point to areas of concern as mistaken, incomplete, or deficient information cultivates assumptions, attitudes, beliefs and values that are inconsistent with what nurses maintain nursing is: a caring healing profession. Recommendations for future research include; larger population studies surveying nurse practitioners using an alternative to electronically delivered methods (or in addition to an electronic survey) to increase the return rate, comprehensive investigation of nurse educators' attitudes, knowledge and self-efficacy for integrating gender and sexual minority content in both undergraduate and graduate education, and lastly, exploration of the extent of sexual and gender minority health care content being included in NP programs and continuing education opportunities.

\section{Acknowledgements}

The author is grateful for the support received from the Research Committee from Regis College: Dr. Joyce Oppenheimer (Chair), Dr. Rebecca Schroeder and Dr. Susan Jo Roberts (Northeastern University College of Nursing, Boston, MA) and to Dr. Stacey Kite from Johnson and Wales University, Providence, RI. Appreciation is also extended to the nurse practitioner association involved in this project and to all nurse practitioners that took part in the study.

\section{References}

[1] Eliason JM, Dibble S, DeJoseph J. Nursing's silence on lesbian, gay, bisexual, and transgender issues: the need for emancipator efforts. Advances in Nursing Science. 2010; 33(3): 206-218. PMid:20520521 http://dx.doi.org/10.1097/ANS.0b013e3181e63e49

[2] Johnson M, Yucha C. Methodological quality of quantitative nursing lesbian, gay, bisexual, and transgender research from 2000 to 2010. Advances in Nursing Science. 2012; 35(2): 154-165. PMid:22565790 http://dx.doi.org/10.1097/ANS.0b013e31825372b9

[3] Institute of Medicine.The Health of Lesbian, Gay, Bisexual, and Transgender People: building a foundation for better understanding. The National Academics Press; 2011.

[4] Chapman R, Watkins R, Zappia T, Nicol P, Shields L. Nursing and medical students'attitudes, knowledge and beliefs regarding lesbian, gay, bisexual and transgender parentsseeking health care for their children. Journal of Clinical Nursing. 2011; 21: 938-945. PMid:22008095 http://dx.doi.org/10.1111/j.1365-2702.2011.03892.x

[5] Rondahl G. Students' inadequate knowledge about lesbian, gay, bisexual and transgender persons. International Journal of Nursing Education Scholarship. Volume 6, Issue 1, Pages -, ISSN (Online) 1548-923X; 2009.

[6] Mayer HK, Bradford BJ, Makadon JH, Stall R, Goldhammer, H, Landers S. Sexual and gender minority health: What we know and what needs to be done. American Journal of PublicHealth; 2008; 98(6): 989-995. PMid:18445789 http://dx.doi.org/10.2105/AJPH.2007.127811

[7] National Center for Transgender Equity. National Transgender Discrimination Survey. 2010. Available from http://www.thetaskforce.org/reports_and_research/ntds. 
[8] U. S. Department of Health and Human Services. Healthy People 2020. Lesbian, Gay, Bisexual and Transgender Health; 2012. Available from http:// http://www.healthypeople.gov/2020/topicsobjectives2020/overview.aspx?topicid=25

[9] Axtell AS, Avery M. Westra B. Incorporating cultural competence content into graduate nursing curricula through community-university collaboration. Journal of Transcultural Nursing. 2010; 21(2): 183-191. http://dx.doi.org/10.1177/1043659609357633

[10] Wallace CB. Toward equity in health: A new global approach to health disparities. NY: NY; Springer Publishing Company; 2008.

[11] Benkert R, Tanner C, Guthrie B, Oakley D. Pohl MJ. Cultural competence of nurse practitioner students: a consortium's experience. Journal of Nursing Education. 2005; 44(5), 225-233. PMid:15916026

[12] Benkert R, Templin T, Myers Schim S, Doorenbos ZA, Bell ES. Testing a multi-group model of culturally competent behaviors among underrepresented nurse practitioners. Research in Nursing \& Health. 2011; 34: 327-341.

PMid:21656784 http://dx.doi.org/10.1002/nur.20441

[13] Kallyaperumal K. Guideline for conducting a knowledge, attitude and practice (KAP) study. Community Ophthalmology. 2004. Available from:

http:/www.birds.cornell.edu/citscitoolkit/toolkit/steps/effects/resource-folder/Guideline\%20for\%20Conducting\%20a\%20KAP\% 20Study\%20\%28PDF\%29.pdf

[14] Hoke MM, Robbins KL. Continuing the cultural competency journey through exploration of knowledge, attitudes, and skills with advanced practice psychiatric nursing students: an examplar. Nursing Clinics North American. 2011; 46, 201-205. PMid:21501731 http://dx.doi.org/10.1016/j.cnur.2011.02.004

[15] Norris LT, Aiken M. Personal access to health care: a concept analysis. Public Health Nursing. 2006; 23(1): 59-66. PMid:16460422 http://dx.doi.org/10.1111/j.0737-1209.2006.230109.x

[16] Brotman S, Ryan B, Jalbert Y. Rowe B. The impact of coming out on health and health care access: The experiences of gay, lesbian, bisexual and two-spirited people. Journal of Health and Social Policy; 2002; 15(1). PMid:12212930 http://dx.doi.org/10.1300/J045v15n01_01

[17] Sanchez FN, Sanchez PJ, Danoff A. Health care utilization, barriers to care, and hormone usage among male-to-female transgender persons in New York City. Journal of Public Health. 2009; 99(4): 713-719.

PMid:19150911 http://dx.doi.org/10.2105/AJPH.2007.132035

[18] Morrison S, Dinkel S. Heterosexism and health care: a concept analysis. Nursing Forum; 2012; 47(2): 123-130. PMid:22512770 http://dx.doi.org/10.1111/j.1744-6198.2011.00243.x

[19] Balsam KF, Molina Y, Beadnell B, Simoni J, Walters K. Measuring multiple minority stress: The LGBT people of color microaggressions scale. Cultural Diversity and Ethnic MinorityPsychology; 2011; 17(2): 163-174. PMid:21604840 http://dx.doi.org/10.1037/a0023244

[20] American Association of Nurse Practitioners NP Facts. 2013. Available from www.aanp.org/ images/documents/ research/

[21] Abbot L, Smith L, Pereyia M, Wyckoff M, Hooton MT. Nurse Practitioners' attitudes, perceptions, and knowledge about antimicrobial stewardship. The Journal of Nurse Practitioners. 2012; 8(5): 370-376. http://dx.doi.org/10.1016/j.nurpra.2012.01.023

[22] Burch A. Health care providers' knowledge, attitudes, and self-efficacy for working with spinal cord injured patients with diverse sexual orientation. (Doctoral dissertation). 2005. Availble from ProQuest Information and Learning Company. (accession 3175668).

[23] Burch A. Health care providers' knowledge, attitudes, and self-efficacy for working with patients with spinal cord injury who have diverse sexual orientations. Physical Therapy. 2008; 88(2): 191-198.

PMid:18029393 http://dx.doi.org/10.2522/ptj.20060188

[24] Swanstrom N. Developing and Implementing a Scale to Acess Attitudes Regarding Transsexuality. (Unpublished master's thesis). 2006. University of North Carolina-Wilmington.

[25] Walker J. Almond P. Interpreting Statistical Findings:a guide for health professionals and students. New York: NY; Open University Press McGraw Hill; 2010.

[26] Bandura A. The explanatory and predictive scope of self-efficacy theory. Journal of Social and Clinical Psychology. 1986; 4(1): 159-171.

[27] Ondrejka D. Affective Teaching in Nursing: connecting to feelings, values, and inner awareness. New York: NY; Springer Publishing Company; 2014. 